\title{
DECISION MAKING IN CENTRAL AFRICA- THE PUBLIC HEALTH SYSTEM IN LIGHT OF THE CHANGING ECONOMY
}

\author{
Nicolae PĂUN, PhD \\ Faculty of European Studies, Babeș-Bolyai University, Cluj-Napoca, Romania \\ nicolae.paun@ubbcluj.ro
}

Eyal BUVILSKI, PhD candidate

Faculty of European Studies, Babeș-Bolyai University, Cluj-Napoca, Romania

eyal.buvilski@gmail.com

\begin{abstract}
This paper aims to characterize the considerations of decision makers in Central African states regarding investment in the health sector. The findings rely on data collected in the research, "intercultural economic diplomacy and cross-cultural encounters in Central Africa after the discovery of natural resources- the case of Equatorial Guinea," which is still in process. The health system in Central Africa is very complex and challenging, and there are extensive activities of international factors. In recent decades many Central African states have undergone significant economic changes as a result of the discovery of natural resources or other economic developments, but despite the awareness of decision-makers to health issues, the average investment as a percentage of GDP is one of the world's lowest. The findings demonstrate that although health system is among the first to benefit from the fruits of an economic change, local decision makers seems to invest in impressive medical institutions, sometimes at the expense of increasing public investment in health per se. The paper argues that if decision-makers cease to view the investment in the public health system as an opportunity for political and image gains, they will probably neglect their tendency to establish impressive medical institutions or to implement projects that are well publicized but will invest in state budgets devoted to health.
\end{abstract}

Keywords: Central Africa, decision making, public health system.

\section{Introduction}

In Central African countries health issues are at the top of the agenda. The awareness of the public to the level of health and medical services is increasing, but at the same time, the relatively low professional capacity of the medical system, combined with poor old infrastructures 
and complex environmental conditions, leads to a situation in which the public health systems are having difficulties in meeting the growing needs of the population. The public health system is very complex and challenging, and there are extensive activities of international factors, headed by the World Health Organization, to assist local governments in meeting their goals (WHO, 2019).

In recent decades many Central African states have undergone significant economic changes as a result of the discovery of natural resources or other economic developments, but the average regional investment in health is still one of the world's lowest (World Bank, 2019). The goal of the international activity in the region is to address urgent health issues, while also raising the awareness of decision-makers so that more resources and attention will be allocated to the health sector. According to the WHO regional office for Africa (2019), African leaders face complex health and environmental challenges that are almost non-existent in other parts of the world. At the same time, they are exposed to pressures from elements within their country who claim that the level of service to the citizen is insufficient, and to international criticism claiming that investment of resources in the public health system is too low, and the priorities are wrong. As a result, decision-makers in Central African countries are subject to ongoing pressures and are expected to show improvement in the performance of the public health system and the level of services provided to the population. This situation leads to the existence of significant but specific projects in various regions aimed at addressing urgent health issues, alongside the establishment of impressive medical institutions designed, among other things, to respond to claims raised by international actors.

Alongside the image considerations, there is also a wide range of considerations for the leaders to improve the standard of living in their country in general and in the health sector in particular. This paper will try to characterize the considerations that guide decision-makers in Central African countries regarding investment in the public health system, from purely professional to internal politics, international image, and personal considerations. The findings rely on data collected in research, "intercultural economic diplomacy and cross-cultural encounters in Central Africa after the discovery of natural resources- the case of Equatorial Guinea," which is still in process. In order to understand the unique context and circumstances of the region, the paper begins with a brief survey of the historical and economic background of Central Africa. 


\section{Central Africa}

The region of central Africa includes eleven countries, nine according to the UN definition (UN Statistic Department, 2019), and together with and Rwanda and Burundi comprise the ECCAS- Economic Community of Central African States (African Union, 2019). Geographically, this area includes the countries adjacent to the drainage basins of the Congo and the Chari rivers, which are a source of livelihood for the inhabitants since early history (Austen \& Headrick, 1983).

The countries of the region have a lot in common, including the life in a hot and humid climate, the vast areas covered by the rain forests, alongside with historical, economic, culture, linguistic and ethnic characteristics (Ross, et al., 2013). In most countries of the region, the governance system is a presidential republic (CIA, 2019), which means that the president is the supreme authority and the decisions are usually made by him or by his immediate surroundings. According to Hermann (2006), Strong leaders do not need to be in a consensus, and institutional limitations is not a primary factor for them. Central African leaders enjoy almost unlimited freedom to make decisions, and this is reflected in the power and influence they have in their hands. According to Ciot (2014), to understand a leader, it is essential to get to know him well, and by idiosyncrasy analysis take into consideration elements like leadership style, emotions, cognitive situation, impressions, and intelligence, in weighing the environmental conditions in which it operates and the pressure exerted on him by the various parties. In Central African countries, it is also essential to understand his ethnic and tribal affiliation. Since Central African leaders are strong, dominant, and widely empowered, it is critical to understand the considerations that guide them, in order to understand their decision-making processes.

\section{Health in central Africa}

According to the African regional health report (2019), Africa in general, and Central Africa in particular, are complex and challenging both in terms of medical issues and in terms of the public health systems. For example, $60 \%$ of the world's HIV/AIDS population is in Africa, more than $90 \%$ of malaria cases that occur worldwide are in Africa, recurrent Ebola outbreaks, various tropical diseases, and more. The report notes an improvement in recent years in various areas, among them a decline in child mortality and success in eradicating the polio virus. However, the population in the region is still at high risk of life-threatening communicable diseases. Noncommunicable diseases, such as hypertension, heart disease, and diabetes, are on the rise. Injuries 
remain among the leading causes of death in the Region. Basic sanitation needs remain unmet for many, for example, only $58 \%$ of people living in sub-Saharan Africa have access to safe water supplies. The report stresses that Africa can move forward on recent progress only by strengthening its fragile public health systems. The various governments of the region are aware of health problems and its implications for improving the standard of living and responding to public needs. In some countries, future planning for the public health system is being carried out. For example, the national plan for economy and development "Horizon 2020" in Equatorial Guinea (Ministerio de Planificacion, 2007), in which following the oil and gas discoveries has carried out a comprehensive economic and social planning for the coming years. Nevertheless, there is a fundamental gap between planning and implementation, and the actual implementation of the ideal vision is still far away in Equatorial Guinea as in other countries in the region (World Bank, 2019).

\section{Traditional medicine}

The health issues in Central Africa involves both modern and traditional methods of medicine, which is an inseparable part of the local culture. When the average African citizen needs medical attention, he usually sees two possibilities - one is to look for the best general medical service he can afford, and the other is to turn to traditional medicine.

According to Mavhungu (2012), traditional medicine in Central Africa has ancient roots in the local culture. Unfortunately, some African cultural traditions cannot be empirically proven and are considered counter to globalization, science, and technology. Therefore, people who deal with it are perceived as underdeveloped, although their unique culture and values must be understood. The same is true for traditional medicine, which is highly regarded and feared by the locals and can be perceived as archaic, outdated, and ineffective in the eyes of foreigners.

Traditional medicine can be divided into two main modes of treatment- traditional medical treatment and spiritual care. The medical treatment includes the use of local herbs, various potions, and relies on traditional medicines and knowledge passed from generation to generation. The basis of spiritual therapy is the perception that the source of the illness or pain is witchcraft caused by the spirit of the enemy. Douglas (1967) was among the first to describe the significance of sorcery and witchcraft in Central Africa, and it is an integral part of life in this region. According to the local perception, people can influence the environment because it is influenced by human actions, 
especially by witchcraft and sorcerers, who have direct spiritual contact. According to this view, the problems of the local people stem from the fact that they cannot control the actions of other people. According to Igwe (2004), sorcery is a dominant belief that affects the mindset and perception of many Africans, both educated and uneducated. In order to advance and join the developed world, Africans must leave the irrational belief in sorcery and magic, and this is especially true as far as health is concerned.

\section{The economy in central Africa}

The history of Central Africa starts at the beginning of humanity, and at the same time also began the economic development of the region. In the 15 th century, the demand for raw materials led to the creation of commercial ties between the region and the non-African world, especially the Islamic Middle East and the Christian Atlantic.

These relations led to a series of economic processes, leading eventually to the creation of foreign colonies of European countries in Africa, first were the Portuguese settlers in Sao Tome, and others followed. The colonists needed labor force, and they first started using local people, and later on brought workers from neighboring regions, leading eventually to the Atlantic slave trade, a critical process which had a profound impact on the Central African region. As the European presence increased, there was a need for more effective governance and bureaucracy systems. The process culminated in the Berlin conference in the years 1884-1885, when the continent was divided between the colonial European countries in a way that each can fully govern the areas under its responsibility (Birmingham \& Martin, 1983).

Over the years, the primary source of income for the Central African region was the natural resources, and many regions relied on only one natural resource. In each period, it was a different natural resource - coal, salt, minerals, diamonds, gold, timber, etc., to crude oil and gas, which are the main export products nowadays. The reliance on export revenues of only one product exposed the local economies to significant risks, as a result of fluctuations in exchange rates or changes in market preferences and reduced demand (Ross, et al., 2013).

The slow economic development of poor countries, including in Central Africa, has troubled many economists and theorists over the years. Various social and economic theories, such as the dependency theory in the 1950s and 1960s, the world system theory 1970s and 1980s, and the analysis of globalization in the 1990s tried to explain processes that influenced the slow 
development (Amin, 2014). As far as Central African countries are concerned, it seems that a relatively simple argument proposed by Gunder Frank (1993) can explain this situation. Development and under-development are two sides of the same coin, whereas the developed world enriches itself by keeping other regions less developed. Less developed countries are becoming a target market for final products, and remain as suppliers of raw materials to the developed countries.

At the individual level, the economy of the Central African region is traditional, mainly based on fishing and agriculture, and is mostly cooperative. Families are helping one another, and children are taking part in the work efforts. In African society, children are perceived as an economic asset and social security to their extended families (Idang, 2015).

Almost all central African countries were under colonial rule until they gained independence during the1960s- the only exception in Angola, who gained its independence from Portugal in 1975. In the years since the countries became independent, most economies have stabilized, and most have undergone significant economic changes as a result of the discovery of natural resources in their territory, mostly oil or gas, among other economic developments. The prominent example is Equatorial Guinea, where GDP per capita rose from about $\$ 700$ in the early 1990s to $\$ 37,400$ in 2017 (CIA, 2019). According to the World Banks' chief economist for Africa, the region's economic development is slower than expected. Policymakers should, among other things, focus on investment that fosters human capital, and boost productivity (World Bank, 2019). Currently, African countries in general, and in particular Central African countries, are characterized by a relatively high level of corruption (Transparency International, 2019), unequal distribution of income, low local production and high reliance on imported products.

\section{Methodology}

The data and findings that were in use during the work on this paper were collected in the framework of a doctoral research "intercultural economic diplomacy and cross-cultural encounters in Central Africa after the discovery of natural resources- the case of Equatorial Guinea," which is still in process. The research attempts to understand, via the local point of view, the history of the region and the changes it has undergone since the discovery of natural resources and the economic change that followed, to define the cultural and business characteristics of the region, and to develop useful recommendations for foreigners seeking to operate in Central Africa. The main 
goal of the research is to develop an intercultural economic diplomacy model for Equatorial Guinea, with recommendations based on the country's unique characteristics. This model will also be suitable for other Central African countries with similar characteristics. The main research question is what components might comprise a model of intercultural economic diplomacy for Central Africa. The research was carried out in the qualitative approach, which means that the findings arrive not by utilizing statistical or other means of quantification (Strauss \& Corbin, 1990). The qualitative research collects its data from the natural system and allows the understanding of personal experience, actions, and motifs, rather than examining existing theories (Hays \& Wood, 2011). The qualitative approach attaches importance to the meaning of things in the eyes of the participants, and in this work refers to the subjective point of view of the African people. The data was collected in the natural system, in Equatorial Guinea, through in-depth interviews and document analysis. Twelve in-depth interviews were conducted with senior ministers and officials in the past and present Equatorial Guinea, and with senior UN officials and business people operating in Central Africa. The interviewees selected to participate in the research are those who have served in key positions during relevant periods, before and after the discovery of oil and gas, or those who can contribute to the research because of their current role or unique experience. The interviewees were chosen based on a personal acquaintance or appropriate recommendations of reliable local people with suitable backgrounds.

The research approach is a case study, which assumes that it is possible to investigate a specific case and learn about the entire group (Yin, 2012; Yosifon, 2016). This research investigates the case of Equatorial Guinea, but the conclusions are relevant to most Central African countries.

The qualitative research consisted of three stages. The first stage aims to describe historical, economic and diplomatic processes, the second stage aims to examine the intercultural economic relations of Equatorial Guinea with the international community, and the third stage aims to develop a working model for Central Africa. The research tools were, in all stages, semi-structured in-depth interviews and document analysis.

\section{Findings}

The findings from the research focus on three main themes. The changes that occurred in the country as a result of the economic change, the modern economic-cultural environment, and 
the country's economic and intercultural relations with the international community. The findings help to understand how locals interpret reality and allow us to describe how decision-makers perceive the public health system and the range of considerations that guide them.

Before describing the findings and the impact of the economic change on the priorities of decision-makers, it is essential to address the issue of corruption in the Central African region. Some of the leaders and their immediate surroundings are accused of corruption and embezzlement of public funds. The international community is very keen on this issue, and it is a matter of dispute with many African governments. Most of the interviewees are aware of the problem of corruption, but in this context, they claimed unfair treatment and hypocrisy from the international community toward Africa. In this research, an attempt was made to bring the local interpretation of historical and economic events and relate to the facts in a practical and non-critical manner.

According to the interviewee's responses in regard of the changes that have taken place in the country as a result of the economic change, it seems that leaders want to improve the standard of living of the citizens, and that treatment of the health system is a high priority. The issue of health is alarming to the public, and the higher the standard of living, the greater the demand for advanced medical services. In the eyes of the average citizen, health services are the medical services provided to the population, but according to decision maker's view, as well as the international community, under this definition, there is a much broader spectrum of services and infrastructures, including water, electricity, urban planning and more. In the eyes of the decision makers, the economic change must be exploited to increase the attractiveness of the state, and raising the issue of health to the top of the priorities is significant, especially for the younger generations. Health achievements are seen and felt in their daily lives and are reflected in the attitude of the international community. The establishment of impressive health institutions in the country is also intended to meet the internal political needs of the leadership. In various Central African countries, modern hospitals are being established, even if they do not meet the exact needs of the population. At the symbolic level, the goal of demonstrating leadership commitment through investments in the health sector is achieved. In this context, some of the interviewees noted that there is an additional gap in the leadership's understanding of the situation in the public health sector- In their simplistic view, countries with advanced public health system must have advanced medical institutions and modern hospitals. Therefore, there is a tendency among Central African 
leaders to promote such projects, considering that this is the best way to narrow gaps compared to developed countries.

According to the interviewee's responses regarding changes in the country's economic and cultural environment, it can be seen that in various African countries, after an economic change, a process of strategic planning began, with the involvement and support of international organizations, including strategic planning for the public health system. For example, the process that began after the discovery of oil and gas in Equatorial Guinea ended in 2007 with the publication of Horizon 2020, the national plan for economic development. The results of the process were, among others, coordinated health campaigns, such as the fight against malaria, the training of professional personnel, and more (WHO, 2017). At the same time, with the improvement in the economic situation, the demand for overseas health services is rising among wealthy Africans, from complicated medical problems to periodic examinations. Despite the economic improvement and the increased demand for general medical services, there is still a high demand for traditional medicine. The social structure in Central Africa, which is based on the division into ethnic groups, tribes, families, villages, and more, was kept after the economic change. In this mode, traditional healers, whether using local herbal remedies or witchcraft and sorcery dealing with the spiritual aspects of therapy, are still relevant and present in daily life. The belief in traditional medicine is extensive in the region, among all levels of the population, educated and non-educated, and is an integral part of the leaders' considerations. The new economic environment in Central Africa is a magnet for business entities that identify the considerable commercial potential that has not yet been realized. The newly developed economies attract business factors that try to influence decision-makers to act in their favor, either directly or indirectly. Business factors that work closely to decision makers are pushing, out of their business interest, to the investment in impressive projects, at the expense of channeling state health budgets to more urgent needs. In some cases, business factors can be found behind a decision to establish a modern medical facility due to their direct business interest in the project. The most significant advantage of the business factors is their ability to execute complicated projects, in a relatively short time, without having to deal with the internal bureaucracy and regulation existing among state entities and international organizations. Business companies can adopt a flexible model of construction and operation, that meets the immediate needs of the state, such as building and operating a hospital, including staffing a professional workforce, installation of advanced medical 
equipment, and ongoing supply of medicines and materials. For the African leaders, this is the fastest and most available solution that helps them establish an advanced medical facility, even without local relevant capacities and professional workforce. One of the problems with the new impressive medical facilities is the accessibility of the services to the general public. Since there are relatively few such medical facilities, with a limited number of hospital beds, they are unable to provide the needed services to the general public. The combination of the local African mentality and the social structure leads to a situation in which the option of receiving medical treatment in those facilities is open only for those who can afford it, or for those who receive financial support from the government. Hence, those medical services are not available to the majority of the population.

According to interviewees responses regarding the intercultural economic relations with the international community, a complex picture emerges. Factors within the international community are involved and professionally accompany public health systems in various countries (WHO, 2017). For Africans, this work, especially that of the World Health Organization, is necessary and welcome. However, in African eyes, it is recommended to conduct this dialogue in terms of cooperation, not just in terms of aid. According to the local perception, the international community is working mainly to prevent the spread of epidemics and assist disaster-stricken areas, while there is also room for more work and advanced medical services in affluent areas and to the ongoing treatment of the population. One of the considerations of a leader's decision to invest in impressive health projects, whether the establishment of a modern hospital or an ambitious health project, is the desire to demonstrate to the international community his commitment to promoting the health sector. Also, there is an expectation among Africans that the work of international actors, especially in the health sector, will be more in partnership with them and less by external intervention.

\section{Discussion and conclusions}

The economic changes that have occurred in many Central African countries in recent decades have led to a change in the economic understanding and behavior of decision-makers, and an improvement in the standards of living of the citizens. As a result, there has been an improvement in the level of medical services provided to the public, and there has been an increase in the expectations for better health services. The public health system in various Central African 
countries presents a complex challenge to decision-makers. The health issues at hand are among the most complicated in the world and put the population under a vast range of risks that often require urgent attention. Beyond that, African leaders' attitude to the health sector is under constant public scrutiny, as well as under the supervision and criticism of the international community. In the Central African health sector, there is a high level of involvement of international organizations, which leads campaigns on urgent medical issues and at the same time, promote awareness among local decision-makers. The pressure exerted on the leaders of the international community does have an impact, but its results are not always optimal. While the average Central African public investment in health is among the world's lowest, leaders choose to hold an impressive project, among other things, in order to serve image interests and internal political needs. Such projects, as modern and well-equipped hospitals, are sometimes set up at the initiative of business entities that can influence decision-makers. The businesspeople are near the decisionmakers and are working to promote projects in which they have an interest, even if things do not accord with the interests of the state.

Through such projects, leaders try to demonstrate their commitment to investment in the public health system, and at the same time to send a similar message to the international community. Even though many of the local leaders have considerable power and influence in their countries, the importance of internal politics, as well as world public opinion in their considerations, are central. In the priorities of the leaders, the fact that it is possible to prevent morbidity by treating infrastructure, for example increasing the amount of fresh water and preventing pollution, is essential, but the complexity of doing it compared with the establishment of an impressive new hospital ultimately defeats the scales.

Another issue is the partial understanding of some African leaders regarding the correct way to promote the public health system. According to African decision-makers view, sometimes an advanced medical facility in their country can be considered as a significant investment in the public health system, while in practice it is only a relatively small investment that does not affect the total budget devoted to health. At the same time, poor infrastructures that might lead to increased morbidity are not adequately treated. In the view of the leaders, the establishment of a modern hospital means reducing gaps compared to more developed countries, whereas in practice, given the current situation in Africa, the priorities should be different. 
In summary, the main conclusions emerging from the study are that in order to influence public health decision-making, it is essential to understand the economic, social and cultural changes that have taken place in the region in recent decades. Because of the centrality of the leaders, it is crucial to understand their considerations. Considerations of internal politics and international image play an important role in decision-making processes, and external pressures strongly influence the attitude toward public health systems in Central Africa. In addition to these considerations, the pressure exerted by business entities is a hindrance to decision-making processes in the Central African region. Increased cooperation with international organizations has definite potential for public health systems, and preference should be given to working with these organizations rather than working with independent business entities. In the framework of international cooperation, the Africans expect to be seen as valuable partners, not only as those in need of assistance. Therefore, it is essential to conduct the dialogue in terms of cooperation and not only in terms of aid. It is recommended to strengthen cooperation and understanding with the African leaders in order to increase their trust in the international system. These measures may prevent a situation in which improving the international image will come at the expense of improving services to the population.

\section{References}

1. African Union, 2019. Economic Community of Central African States (ECCAS) | African Union.

[Online]

Available

at:

https://au.int/en/recs/eccas

[Accessed 161 2019].

2. Amin, S., 2014. Capitalism in the Age of Globalization- The Manaegment of Contemporary Society. 2nd ed. London: Zed Books.

3. Austen, R. A. \& Headrick, R., 1983. Equatorial Africa Under Colonial Rule. In: D. Birmingham \& P. M. Martin, eds. History of Central Africa. London: Longman.

4. Birmingham, D. \& Martin, P. M., 1983. History of Central Africa. 1st ed. London: Longman. 
5. CIA, 2019. The World Factbook - Central Intelligence Agency. [Online] Available at: https://www.cia.gov/library/publications/resources/the-world-factbook/ [Accessed 65 2019].

6. Ciot, G.-M., 2014. Negotiation and Foreign Policy Decision Making. 1st ed. Newcastle upon Tyne: Cambridge Scholars.

7. Douglas, M., 2012. Witch Beliefes in Central Africa. Africa, 37(1), pp. 72-80.

8. Gunder Frank, A., 1993. The 5,000-Year World System. In: A. Gunder Frank \& B. K. Gillis, eds. The World System- Five hundred years or five thousand?. New York: Routledge, pp. 3-58.

9. Hays, D. \& Wood, C., 2011. Infusing qualitative traditions in counseling research designs. Journal of Counseling and Development, 3(89), pp. 288-295.

10. Hermann, M., 2006. Assessing Leadership Style: Trait Analysis. The psychological assessment of political leaders, pp. 178-212.

11. Idang, G., 2015. African Culture and Values. Phronimon, 2(16).

12. Igwe, L., 2004. A Skeptical Look at African Witchcraft and Religion. Altadena, 1(11), pp. 72-74.

13. Mavhungu, K., 2012. Witchcraft in Post-Colonial Africa: Beliefs, techniques and containment strategies. Bamenda: Langaa Research \& Publishing.

14. Ministerio de Planificacion, 2007. Plan Nacional de Desarrollo Economico y Social, Bata: Government of Equatorial Guinea.

15. Ross, R., Hinfelaar, M. \& Peša, I., 2013. The Objects of Life in Central Africa : The History of Consumption and Social Change, 1840-1980. 1st ed. Leiden: Brill.

16. Strauss, A. \& Corbin, J., 1990. Basics of qualitative research. Thousand Oaks: Sage Publications.

17. Transparency International, 2019. Transparency International - The Global AntiCorruption Coalition.

[Online]

Available at:

https://www.transparency.org/

[Accessed 254 2019].

18. UN Statistic Department, 2019. UNSD - Methodology. [Online] Available at: $\quad$ https://unstats.un.org/unsd/methodology/m49/\#geo-regions [Accessed 161 2019]. 
19. WHO Regional Office for Africa, 2019. Regional Office for Africa. [Online] Available at:

https://www.afro.who.int/ [Accessed 234 2019].

20. WHO, 2017. The African Regional Health Report: The Health of the People. [Online] Available at: https://www.who.int/bulletin/africanhealth/en/ [Accessed 234 2019].

21. WHO, 2019. The African Regional Health Report: The Health of the People. [Online] Available at: https://www.who.int/bulletin/africanhealth/en/ [Accessed 234 2019].

22. World Bank, 2019. Office of the Chief Economist, Africa Region (AFRCE). [Online] Available at: $\quad$ https://www.worldbank.org/en/region/afr/brief/afrce [Accessed 254 2019].

23. Yin, R. K., 2012. Applications of case study research. 3rd ed. Thousands Oaks: Sage Publications.

24. Yosifon, M., 2016. Case study. In: N. Sabar-Ben Yehoshua, ed. Traditions and Genres in Qualitative Research- Philosophies, Strategies and Advanced Tolls. Tel Aviv: Mofet Institute, pp. 179-216. 